\title{
A CONSTRUÇÃO DO MONSTRO A PARTIR DO ACONTECIMENTO JORNALÍSTICO - UMA LEITURA SOB A ÓTICA DE PEIRCE
}

ANDRIO SANTOS

UNIVERSIDADE FEDERAL DE SANTA MARIA SANTA MARIA, RIO GRANDE DO SUL, BRASIL E-MAIL: ANDRIO_LABRIE@HOTMAIL.COM JANAIINE DOS SANTOS UNIVERSIDADE DE CRUZ ALTA CRUZ ALTA, RIO GRANDE DO SUL, BRASIL E-MAIL: SJANAINES@GMAIL.COM

HTTP://DX.DOI.ORG/10.5902/2316882X14842 


\section{A CONSTRUÇÃO DO MONSTRO A PARTIR DO ACONTECIMENTO JORNALÍSTICO - UMA LEITURA SOB A ÓTICA DE PEIRCE}

Resumo: O presente artigo traz as fundamentações e resoluções da pesquisa homônima, que pretende discutir o papel da figura do monstro mítico no imaginário social humano. Para tal, foi realizada uma análise semiótica do caso do canibal Jorge Negromonte. Para fundamentações teóricas e críticas utilizam-se autores como Peirce, Durand, Santaella e Henn. Palavras-Chave: Mito; Semiótica; Símbolo; Imaginário; Acontecimento.

\section{A CONSTRUÇÃO DO MONSTRO A PARTIR DO ACONTECIMENTO JORNALÍSTICO - UMA LEITURA SOB A ÓTICA DE PEIRCE}

Abstracto: Este trabajo presenta los fundamentos y las resoluciones de la investigación del mismo nombre, que trata sobre el papel de la figura del monstruo mítico en humanos imaginario social. Para ello, se realizó un análisis semiótico del caso del caníbal Jorge Negromonte. Por los fundamentos teóricos y de uso-autores críticos, como Peirce, Durand Santaella y Henn.

Palabras clave: Mito; Semiótica; Symbol; imaginários; Evento.

THE CONSTRUCTION OF THE MONSTER FROM THE JOURNALISTIC EVENT - A READING FROM THE PERSPECTIVE OF PEIRCE

Abstract: This paper presents the foundations and resolutions of the homonymous research, which aims to discuss the role of the figure of the mythical monster in human social imaginary. To this end, a semiotic analysis of the case of the cannibal Jorge Negromonte was performed. For theoretical and critical foundations were considered authors like Peirce, Durand, Santaella and Henn.

Keywords: Myth; Semiotics; Symbol; Imaginary; Happening. 


\section{INTRODUÇÃO}

É na consciência humana onde se proliferam as especificidades do imaginário, é onde algo sublima, constrói e reconstrói hábitos, crenças, conceitos. O imaginário tem seu caráter fantástico e há séculos o homem induz sobre o mundo que o cerca. Metafísicos, filósofos e alquímicos. Das ciências antigas vieram muitos fatos hoje comprovados. Seria no pensamento nascente e puro onde se dão as descobertas e é dessa forma também que surgem os mitos. Assim também se originam os monstros. Uma cultura específica tem o poder de criar seus próprios monstros e, verdadeiramente o faz, sendo que cada monstro só pode nascer, crescer e gerar descendentes dentro de uma cultura que o alimente e sustente, tanto em suas glórias, quanto em seus medos, mas de fato dando-lhe atenção.

A monstruosidade seria entendida como uma transgressão das leis estabelecidas e geraria, através de sua presença singular, o sentimento de temor, dúvida, aviso contra infrações ou punição. O monstro, na verdade, seria aquele que "mostra" alguma coisa: a ira de Deus, uma revelação divina, as inúmeras possibilidades da natureza ou aquilo que o homem pode vir a ser. E na sua particularidade, representa uma alteração maldita ou bendita das regras conhecidas.

Até o início do século XIX, o monstro era identificado pelo corpo, ou seja, pelas suas características estéticas. A importância atribuída ao fato da criatura ser sábia, inculta ou perigosa, era reduzida, pois a estrutura física era o que caracterizava monstro. Um exemplo disso é que no século $\mathrm{XVI}$, com o despontar da caça às bruxas, também envolvendo uma questão de alteridade,

[...] a igreja vai identificar o ser delinquente, satânico e anormal na figura da mulher, preferencialmente a feiticeira, o corpo estranho por excelência em uma cultura fundamentalmente organizada em torno de valores inventados como "masculinos" (LEITE JÚNIOR, 2007) ${ }^{1}$.

1 Do artigo "O que é um monstro", publicado em 10 de setembro de 2007, por "Com Ciência, Revista Eletrônica de Jornalismo Científico. http://www.comciencia.br/ comciencia/?section=8\&edicao=29\&id=340. Acesso em 19/09/2012.

Rev.Cad.Comun. Santa Maria, v.20, n.2, art 2, p.3 de 19, maio/ago.2016 
Ainda no século XIX surgiram os freakshows² . Apresentações de coisas estranhas envolvendo o caráter físico humano tornaram-se sucesso na Europa. Mais tarde, essa cultura alcança a América do Norte e se solidifica como um negócio extremamente rentável. Nos freak shows o bizarro é o espetáculo e seu sucesso tem base nas anomalias e deformidades humanas. Mas a partir da metade do século XIX, devido aos avanços da tecnologia e da medicina, a concepção de monstro acabou migrando do corpo, do estado físico do ser, para a mente. "O mundo exterior não traz mais 'maravilhas', apenas aleijões, restou ao homem moderno procurar os encantos e horrores do mundo fantástico dentro de si mesmo" (LEITE JÚNIOR, 2007) $)^{3}$.

A concepção de monstro que perdura até os dias de hoje é a figura do indivíduo anormal em si mesmo, que se adapta a esta condição - transformando-se de uma aberração física para a de uma vítima ou doente que precisa de tratamento medicinal. O monstro agora é o assassino, o ladrão, o psicopata, o maníaco em todas as suas formas e variedades de perturbações da psique humana. Às luzes do século XX, as áreas específicas da psique, como a psicologia e a psiquiatria, elegem então as novas aberrações modernas - o monstro interiorizado.

Contudo, o debate sobre o monstro não se aproximou de uma conclusão. Haveria ainda a transferência dos medos da sociedade para tal figura monstruosa, ou seja, o mito do monstro seria encarnado em inúmeros indivíduos e teria relação estreita com as situações cotidianas de agressão impregnadas na sociedade.

\section{DESENVOLVIMENTO}

Apresentam-se aqui a fundamentação teórica e crítica que norteia o trabalho. As subseções a seguir tratam do monstro e sua construção histórica, trazem referências da sua imagem mítica e sua potencialidade semiótica enquanto símbolo. Ainda, apresentam algumas de suas relações

2 Um freakshow (Show de horrores) é uma exposição de raridades biológicas, referidas como "aberrações da natureza". Surgiram na Europa no século XIX e se tornaram imensamente populares.

3 Do artigo "O que é um monstro", publicado em 10 de setembro de 2007, por "Com Ciência, Revista Eletrônica de Jornalismo Científico. http://www.comciencia.br/ comciencia/?section=8\&edicao=29\&id=340. Acesso em 19/09/2012.

Rev.Cad. Comun. Santa Maria, v.20, n.2, art 2, p.4 de 19, maio/ago.2016 
com o imaginário social e o acontecimento jornalístico.

\subsection{A Crença}

O monstro teria origem a partir de crenças. Seria estabelecido pela forma de pensar de uma época, dando-se por trato ou pacto social, sempre gerado de um pensamento. O pensamento é o que gera a crença e uma crença nada mais é do que algo que se torna comum, que age sobre o indivíduo e que repercute, após fixar-se, em sua posterior maneira de pensar. Segundo Peirce, crença:

[...] é a meia-modulação que encerra uma frase musical na sinfonia de nossa vida intelectual. [...] 0 remate final do pensamento é o exercício de volição (definição), de que o pensamento já não faz parte; mas a crença é apenas um estágio de ação mental, efeito sobre a nossa natureza produzido pelo pensamento que influenciará a reflexão futura (PEIRCE, 1972, p. 56).

Observa-se ainda que "A essência de uma crença é a criação de um hábito, e diferentes crenças se distinguem pelos diferentes tipos de ação a que dão lugar" (PEIRCE, 1972, p. 56). Tal colocação diz respeito ao fato de que a repetição de uma ação é o que fundamente um hábito, pois seria desta sucessão de fazeres que surge algo costumeiro e definido que cristaliza-se num indivíduo. O hábito definido seria, por sua vez, o que fundamenta a crença, o que a origina. Nesta instância, justamente o que faz diferir uma crença de outra é esta repetição de ações, pois cada crença tem seu conjunto próprio de hábitos.

Dessa definição é que vem justamente o que se pode entender como algo real. Segundo Charles Peirce, "a opinião que será, afinal, sustentada por todos os que investigam [...] é o que entendemos por verdade, e o objeto que nesta opinião se representa é o real” (PEIRCE, 1972, pág 57). Logo, em muitas instâncias, a crença pode induzir o real, fomentando-lhe o poder e fixando-o no pensamento. Se se acredita que uma coisa é real, assim ela se torna, mesmo que de um ponto de vista espiritual ou abstrato em qualquer forma.

Nessa acepção, poder-se-ia discorre sobre como os mitos se formam na consciência através da crença, pois tudo acontece na mente e recebe significado por ela, a partir da realidade reconhecida pelo indivíduo, sua ideologia e hábitos. Assim, esse processo mental se daria devido à própria

Rev.Cad.Comun. Santa Maria, v.20, n.2, art 2, p.5 de 19, maio/ago.2016 
obscuridade subjetiva do pensamento de um indivíduo em relação a sua forma de interpretar uma sensação produzida. Isto porque nada seria explicito e haveria apenas qualidades e sugestões para serem decodificadas e interpretadas pela mente.

Imaginamos contemplar, no objeto, uma qualidade especialmente misteriosa; e se nossa concepção nos for posteriormente apresentada sob forma clara, não a reconhecemos, devido a ausência da sensação de ininteligibilidade. Enquanto perdura, o engano coloca, obviamente, invencível obstáculo no caminho do pensamento perspicaz (PEIRCE, 1972, p. 57).

O que se tenta ilustrar aqui é que as qualidades do que se percebe no objeto do pensamento não são necessariamente as próprias qualidades deste, mas sim uma percepção que sem tem dele. Assim, o indivíduo formaria uma imagem idealizada deste objeto e ao ver-se posteriormente frente ao significado claro e conciso, não seria capaz de reconhecê-lo, devido à concepção já existente. Segundo Peirce, "sempre é possível serem elas (as nossas ideias) claras sem serem verdadeiras" (PEIRCE, 1972, p. 57). Por isso a crença fundamentaria o mito e por ser o monstro um existente mítico, se vale dos mesmos preceitos.

\subsection{A semiótica de Peirce}

Como ferramenta de análise do caso apresentado, utiliza-se a semiótica fundamentada por Charles Sander Peirce. A base para a sua compreensão está na fenomenologia, ciência da observação dos fenômenos. Através dela, pode-se desvendar como o pensamento humano é capaz de gerar significados. A fenomenologia "através da análise, postula as formas ou propriedades universais desses fenômenos" (SANTAELLA, 2005, p. 29).

Esta referida análise se dá em três instâncias de pensamento, que se relacionam entre si, funcionando de forma cíclica, definidas por Peirce como primeiridade, secundidade e terceiridade. A primeiridade diz respeito ao visceral, a como as qualidades são captadas pela mente do indivíduo. É a primeira percepção de alguma coisa ou sentimento, é subjetiva e distante da superfície da consciência. Segundo Lúcia Santaella, primeiridade é “[...] uma consciência imediata tal qual é. Nenhuma outra coisa senão pura qualidade de ser e de sentir. A qualidade da consciência imediata é uma impressão (sentimento) in totum, indivisível, não analisável, inocente e frágil

Rev.Cad. Comun. Santa Maria, v.20, n.2, art 2, p.6 de 19, maio/ago.2016 
(2005, p. 35). A secundidade é a ligação com o existente, com o mundo reconhecível, com seus sentidos e conceitos. A secundidade "está ligada às ideias de dependência, determinação, dualidade, ação e reação, aqui e agora, conflito, surpresa, dúvida" (SANTAELLA, 2008, p. 7). O estágio seguinte é chamado terceiridade, quando os sentidos passam a ser pensados, oferecendo ao indivíduo a capacidade de apreensão e cognição. É neste estágio da fenomenologia que ocorre o desvendamento do pensamento, a interpretação do mundo. A terceiridade "diz respeito à generalidade, continuidade, crescimento, inteligência” (SANTAELLA, 2008, p.7). A fenomenologia, assim, é o campo onde se dá a apreensão dos signos. Um signo é qualquer coisa capaz de representar, é "Uma coisa que representa outra coisa: seu objeto" (SANTAELLA, 2005, p. 47). Signos possuem objetos e interpretantes, conforme definido por Peirce. O objeto do signo é aquilo que ele substitui, aquilo que o signo está apto a representar, como a fotografia de uma casa é o objeto do signo, que é a casa em si. O interpretante do signo é o efeito causado por este, são as possibilidades de representar do signo, a maneira como ele se mostra e é apreendido. Ainda seguindo o mesmo exemplo, o interpretante poderia indicar se a casa está em bom estado, se é velha, se possui um estilo arquitetônico específico, etc.

Embora um signo seja algo que representa outra coisa, ele não é verdadeiramente esta outra coisa, apenas a substitui. Esse sentido que o signo carrega afeta a mente do indivíduo que o apreende e, nesta, gera um significado referente ao próprio objeto do signo. Mas o signo só possui capacidades de significar, só pode funcionar como signo se existir uma mente que o perceba e o apreenda. As capacidades de representar de uma mente estão diretamente ligadas aos seus conceitos preestabelecidos, que por sua vez, estão ligados à historicidade, a localização sociocultural do indivíduo no mundo, no tempo e no espaço.

Peirce ainda definiu tríades sígnicas, ou seja, relação de significação estabelecidas de três a três. Para o estudo do caso foram utilizados os pressupostos que compõe a relação do signo com seu objeto. Assim, a primeiridade dessa relação se dá na forma de um ícone, signo que se manifesta em uma simples qualidade. $O$ ícone é carregado de sentidos que agem sobre a mente durante o processo semiótico, ele direciona a ressignificação que o pensamento realiza e seu objeto "[...] é sempre uma simples possibilidade, isto é, possibilidade do efeito de impressão que ele

Rev.Cad.Comun. Santa Maria, v.20, n.2, art 2, p.7 de 19, maio/ago.2016 
está apto a produzir ao excitar nosso sentido" (SANTAELLA, 2005, p.64).

O sucessor do ícone é o índice, um signo segundo que funciona fazendo menção à outra coisa com a qual está conectado de alguma maneira. Se o ícone é qualidade, o índice determina algo real, existente, a que está inegavelmente atrelado nas suas capacidades de significar. "Rastros, pegadas, resíduos, remanências são todos índices de alguma coisa que por lá passou deixando suas marcas. Qualquer produto do fazer humano é um índice mais explícito ou menos explícito do modo como foi produzido" (SANTAELLA, 2005, p. 66).

O símbolo, por sua vez, é um signo de terceiridade e não representa seu objeto devido a uma característica de qualidade, nem por estabelecer com ele uma relação de fato, mas sim, adquire seu poder de representar através de uma lei fundamentada em convenção ou pacto social. O símbolo é um signo geral, que acaba gerando um significado também geral.

[...] o símbolo não é uma coisa singular, mas um tipo geral. E aquilo que ele representa também não é um individual, mas um geral. Assim são as palavras. Isto é: signos de lei e gerais. A palavra mulher, por exemplo, é um geral. O objeto que ela designa não é esta mulher, aquela mulher, ou a mulher do meu vizinho, mas toda e qualquer mulher. $O$ objeto representado pelo símbolo é tão genérico quanto o próprio símbolo (SANTAELLA, 2005, p. 67).

O símbolo pressupõe o ícone e o índice. No processo de construção de sentido, o índice está carregado de ícones, de qualidades e capacidades abstratas de despertar a significação, assim como um símbolo está carregado de índices, pois todo símbolo carrega as marcas que o construíram como tal.

Pela historicidade, o monstro representaria um receptáculo onde o homem injeta seus medos, sua fé, sua crença, a maneira como agiu e age pelos séculos afora dentro do poder de significação humano. O monstro é um tipo geral, pois é uma figura carregada de significados, mas que não é definida como este ou aquele monstro. O monstro é como uma aura caracterizada devido a suas capacidades icônicas e indicais. Assim, no processo semiótico, o monstro é um signo terceiro e simbólico.

Rev.Cad. Comun. Santa Maria, v.20, n.2, art 2, p.8 de 19, maio/ago.2016 


\subsection{O imaginário, a imagem e o mito}

Para que fosse possível discorrer sobre a relação da figura do monstro com a sociedade, fez-se necessário atentar para dois pontos que podem ser determinantes a esta análise: o imaginário e o mito. É no pensamento onde se dá processo semiótico de geração de sentido e este seria floreado pelas funções da imaginação. O campo do imaginário, por sua vez, é composto, de um modo geral, das imagens, símbolos, sonhos, aspirações, mitos, fantasias, muitas vezes pré-racionais e com forte conotação afetiva que existem e circulam nos grupos sociais.

Os mitos extrapolam o imaginário em vertentes e potências muito variadas, demonstrando características de ritualização, idealização do real - campos paradisíacos, terras devastadas, cenários inóspitos - sacrifício e utopia épica, principalmente na figura dos heróis e monstros clássicos. Os símbolos, unidades de significação que compõem o mito, acabam por assumir uma capacidade de projeção de medos ou desejos, de interesses e repulsas, assim, agindo sobre o comportamento de um ser.

O imaginário é o reino da imagem que, segundo a fenomenologia, "é uma consciência e, portanto, como qualquer consciência, é antes de mais nada transcendente" (DURAND, 1996, p. 22). A imagem possui características de segundidade, pois a imagem é capaz de diferenciar a forma como se ressignifica a partir de dado signo, dos outros modos de consciência. Isto quer dizer "que o objeto imaginado é dado imediatamente no que é, enquanto o saber se forma lentamente por aproximações sucessivas" (DURAND, 1997, p. 22). Assim, a imagem é transcendental e arquetípica. O poder verdadeiro da imagem não está nas suas raízes e na sua capacidade arquetípica para garantir um significado, mas sim, em suas propriedades que garantem a mente à liberdade de significar, de reconstruir e renovar sentidos. Como Durand melhor ilustra, "As imagens não valem pelas raízes libidinosas que escondem, mas pelas flores poéticas e míticas que revelam" (1997, p. 39).

Desse modo, poder-se-ia aferir que o imaginário serve como meio onde se propaga o caráter de representação do objeto, ou seja, o lugar onde o signo ganha vida através do poder do indivíduo de significar segundo seus medos, anseios, percepções, logo, tudo aquilo que pode agir como um índice frente ao processo semiótico.

Rev.Cad.Comun. Santa Maria, v.20, n.2, art 2, p.9 de 19, maio/ago.2016 
O imaginário não é mais do que esse trajeto no qual a representação do objeto se deixa assimilar e modelar pelos imperativos pulsionais do sujeito, e no qual, reciprocamente [...] as representações subjetivas se explicam pelas acomodações anteriores do sujeito ao meio objetivo (DURAND, 1997, p. 41).

Seria justamente esse poder de libertação e a característica transcendental possuída pelo imaginário que confeririam ao símbolo suas propriedades tão únicas de significar. Isso porque o símbolo não deve, tangido pelas características do imaginário, ser julgado por uma forma, mas pelo poder que possui, genérico e incisivo. Por isso Durand retoma proposições de Bachelard e coloca que "a imagem literária [...] transcende a forma e é 'movimento sem matéria"' (DURAND, 1997, p. 47).

O mito se constitui de uma narrativa atemporal repleta de símbolos - que estão também fundamentados no imaginário. O mito é então algo que se extrapola dentro do imaginário, que nasce e cresce, ganhado vida e força, atingindo uma forma dentro da consciência unicamente porque as características do imaginário permitem, pois estas fundamentam um campo fértil para tal desenvolvimento. Assim, para entendimento, o mito pode mesmo ser comparado a uma canção, uma música a qual recebe um sentido verbal pelo ritmo e, a partir disso, a capacidade de mudar o mundo incidindo sobre formas de pensamento. Símbolos recorrentes que compõem o mito podem ainda estabelecer ligações com o drama, ou seja, com uma qualidade que se relaciona a sentidos como bem e mal, neste caso, um mal monstruoso.

O monstro assim, composto pelas características presentes num pressuposto de maldade - má aparência, violência, caráter fantástico - agiria como uma fuga imaginária que "dar-se-á necessidade moral e vital" (DURAND, 1997, p. 372). Desse modo, afere-se o valor do monstro dentro do mito e este, por sua vez, seria relevante frente às concepções de mundo do indivíduo.

\subsection{0 acontecimento jornalístico}

Baseado em Giles Deleuze (1998), Ronaldo Henn caracteriza o acontecimento jornalístico como uma singularidade. Algo sistemático, que serve como estopim de um processo. É algo que já existe, como coloca Henn:

Rev.Cad. Comun. Santa Maria, v.20, n.2, art 2, p.10 de 19, maio/ago.2016 
Pré-existente às coisas e articula-se como puro devir [...]. Pela lógica de C. S. Peirce estaríamos no universo da primeridade, território virtual dos acasos. Acontecimento, desta forma, é algo da ordem do inapreensível e que se desdobra nas curvas de intermináveis paradoxos (HENN, 2010, p. 77).

O mesmo autor afere que o acontecimento é uma coisa caracterizada como superficial, mas que em movimentos sequenciais, como séries e cadeias, "nos submerge ao que ele chama de estados das coisas" (HENN, 2010, p. 77). Há concordância em se dizer que o acontecimento é um fato explicável como "um encadeamento - ele é um fim que culmina tudo o que o precedeu - e inscrito num contexto causal" (HENN, 2010, p. 78). Ainda, o acontecimento pode proporcionar a capacidade de se captar novos sentidos e assim produzir novas significações.

Quando se adota uma visão semiótica do acontecimento, pode-se conceber que ele contém em si "a força propulsora da semiose: apreendido na condição de signo, o irromper da sua existência desdobra-se em infinitas possibilidades de desvendamento do objeto em que encarna" (HENN, 2010, p. 79). Isso quer dizer que o acontecimento, como um catalisador de geração de significado, poderia ter relação com um processo de semiose infinita, uma vez que oferece nichos de onde podem brotar diversos significados. $\mathrm{O}$ ato de desvendar o acontecimento seria o combustor desse processo.

O acontecimento estaria localizado no nível do objeto. Henn (2010) lembra as considerações de Antunes (2008), observando que "A narrativa, ao compor eventos, motivos, atores, produz um relato que representa o acontecimento jornalístico em uma dada configuração temporal que agencia ação e interpretação" (HENN, 2010, p. 85). Assim, entende-se que o acontecimento supõe uma ideia de construção. Por isso, como cita Henn, para autores como Alsina (1989), o acontecimento faz parte da:

Construção social da realidade já que ele seria formado pelos elementos exteriores ao sujeito (objeto) que passa a reconhecê-lo e constituí-lo como acontecimento. Ele só tem sentido na medida em que afeta sujeitos ou [...] agindo no campo da experiência (que o transforma em signos) (HENN, 2010, p. 86).

Assim, o acontecimento auxilia a tramar as teias da realidade aceita como tal, porque é reconhecido como fato dissonante e particular no meio

Rev.Cad.Comun. Santa Maria, v.20, n.2, art 2, p.11 de 19, maio/ago.2016 
social, agindo na produção de sentidos dentro dos seus potenciais específicos. No âmbito do jornalismo - na sua capacidade e processos de produção da notícia, com sua lógica e códigos - há a capacidade de apreender o acontecimento e disseminá-lo através dos meios para a sociedade. "será através do jornalismo que o acontecimento na condição de signo ganhará textura definitiva" (HENN, 2010, p. 87).

O significado do acontecimento é construído pelas notícias conforme estas se disseminam, todavia, suas capacidades de significar são afetadas por características emocionais. Desse modo, “[...] o seu significado intelectual, próximo de uma primeira forma de elaboração histórica, esvazia-se em proveito das suas virtualidades emocionais" (HENN, 2010, p. 88). Ou seja, o significado intelectual do acontecimento é afetado pela manipulação das suas potencialidades: a saturação do uso da imagem, da diagramação, de tipos gráficos diferenciados para articular um apelo visual que intenta atrair o indivíduo ou, ainda, despertar um sentimento geral ou específico.

Assim, o acontecimento tomaria configurações particulares, relacionadas à ressignificação de cada indivíduo que o apreende. Proporcionaria, nessa acepção, experiências únicas, capazes de gerar novas significações. Ainda, o jornalismo seria, muitas vezes, referência no que se chama de "Representação da realidade". Mas essa realidade, para que seja assim representada, é preciso que esteja já inserida no sujeito, de uma maneira presente, constituída e interiorizada. Meditsch coloca que uma forma de exemplificar a maneira como a realidade é subjetivamente apreendida pelos indivíduos é observar "como uma pessoa que acorda pela manhã se transporta do mundo dos seus sonhos ao mundo da realidade cotidiana, [...] o jornal é como um dos índices do mundo real que esta pessoa terá a seu dispor" (2010, p. 22 - 23). Ilustra-se aqui a função do índice sígnico, referência a algo real, no seu caráter físico-existencial que auxilia o individuo a reconhecer o mundo. $O$ jornalismo contribuiria então para o processo de manutenção da realidade. Seu poder estaria nas suas formas de discurso, no modo como se comunica com o sujeito que absorve seus produtos midiáticos:

[...] A maior parte da conservação da realidade na conversa é implícita, não explicita. A maior parte da conversa não define em muitas palavras a natureza do mundo. Ao contrário, ocorre tendo por pano de fundo um mundo que é tacitamente acei-

Rev.Cad. Comun. Santa Maria, v.20, n.2, art 2, p.12 de 19, maio/ago.2016 
to por verdadeiro. Assim, uma troca de palavras [...] implica um mundo inteiro dentro do qual estas proposições aparentemente simples adquirem sentido (BERGER E LUCKMANN, 1985, p. 203).

Neste ponto, aborda-se o "senso comum", essa caracterização da realidade que afirma a própria realidade, a maneira como os indivíduos a apreendem e a significam e, ainda, dentro desse padrão, sua importância em relação ao "jornalismo informativo enquanto forma social de produção de conhecimento" (MEDITSH, 2012, p. 23). Meditsh ainda cita Van Dijk para caracterizar o senso comum:

Concluindo, devemos enfatizar que, se o senso comum é identificado como as crenças gerais de uma cultura e se o surgimento das ideologias enquanto crenças de grupos específicos são baseadas em tal campo comum, as ideologias enquanto tal não são uma forma de senso comum (VAN DIJK apud MEDITSH, 2010, p. 36).

Desta forma, o senso comum é algo extremamente pertinente ao imaginário social em suas instâncias e cargas representativas. A cultura seria a vida de uma sociedade, viva no cotidiano ou na memória, e "se a cultura está para as sociedades assim como a memória para os indivíduos, como afirmam os antropólogos, é o senso comum a sua principal forma de manifestação" (MEDITSH, 2012, p. 36).

\section{O CANIBAL - CASO ANALISADO}

À exposição do caso, pretende-se discorrer acerca de como o monstro mítico, como um símbolo, se relaciona com imaginário social, tendo o jornalismo como mediador, através do acontecimento. $O$ caso aqui referenciado tem como cenário a cidade de Garanhuns, em Pernambuco, e figurou na mídia entre março e julho de 2012. Jorge Beltrão Negromonte da Silveira, de 50 anos, sua esposa, Isabel Cristina Pires da Silveira, 51, e sua namorada Bruna Cristina Oliveira da Silva, 25 anos, foram presos e acusados pelo assassinato de duas mulheres em Garanhuns e uma em Olinda. A polícia não descarta possibilidade de mais vítimas.

De acordo com a polícia e informações divulgadas pela mídia, o trio de amantes formou uma seita, a qual acreditava na purificação do mundo através do consumo da carne humana. Além disso, a esposa de Negro-

Rev.Cad.Comun. Santa Maria, v.20, n.2, art 2, p.13 de 19, maio/ago.2016 
monte produzia empadas com a carne das vítimas, vendidas na cidade. A figura de Negromente foi vista com repulsa pela comunidade local. A alcunha de "monstro" foi firmada quase que instantaneamente após a divulgação da prisão e do nome do assassino das jovens.

Para o estudo do caso, foram analisadas quatro reportagens de veículos online. O material escolhido apresenta duas formas distintas de exposição dos fatos. Duas matérias, dos portais de notícias G1 e Uol, foram selecionadas por se adequarem aos princípios de imparcialidade. Outras duas foram selecionadas por serem parciais, tecendo opiniões, como no caso do jornal "O Povo", de Pernambuco. O veículo alega que Negromonte registrou as mortes em um livro "com frieza", quando, na verdade, o livro não relata nada além de memórias de um período de tratamento à esquizofrenia.

O objetivo aqui não é discutir a credibilidade dos veículos jornalísticos que noticiaram o caso, mas sim verificar qual é o impacto causado pela revelação do crime. $O$ caso foi analisado a partir das perspectivas semióticas de Charles Sanders Peirce. A figura de Jorge Negromonte foi posta em análise para que se verifique sua relação com as tríades de relações dos signos. A análise foi direcionada para a relação do signo com seu objeto. Nesta tríade, em sua terceiridade, se encontra o símbolo como signo, o qual, segundo a proposta deste estudo, seria a representação semiótica do monstro mítico. Assim, pode-se chegar a um argumento coerente no que diz respeito ao papel do monstro simbólico no imaginário de uma sociedade contemporânea.

\subsection{Resultados e discussões}

O símbolo é um signo terceiro, da tríade de relação com o objeto e, no caso estudado, abarca a figura do monstro. O crime, no caso, assassinato e canibalismo, foi associado a algo "monstruoso". Dessa forma, foi-se sugerido que apenas um monstro seria capaz de praticar atos descritos como "atrocidade" dentro dos padrões da sociedade. Atrocidade esta que desperta o sentimento de horror e/ou de medo. $O$ entremeio entre o sentimento que o signo desperta e o monstro que cometeu o crime é um índice: o rastro, a prova, o vestígio de que o crime realmente aconteceu.

Jorge Negromonte não pode ser um símbolo, pois não é um tipo geral, ele é o assassino, o culpado confesso de três mortes e do ato de caniba-

Rev.Cad. Comun. Santa Maria, v.20, n.2, art 2, p.14 de 19, maio/ago.2016 
lismo. Assim, sua capacidade de significar é indicial, pois sugere o terceiro geral, neste caso, o monstro. O monstro por sua vez é associado a Negromonte pois este cometeu atos que, por questões morais, repletas de cargas históricas de significação e que são também implicações reais do acontecimento, sugerem a figura do monstro.

Assim, o monstro mítico existiria porque a figura de Jorge Negromonte, através de seus crimes, teria feito surgir índices, imbuídos de qualidades e sentimentos viscerais (ícones), que relacionam sua própria figura, através de seus crimes, dentro de determinações preconcebidas, de trato e convenção social, ao monstro simbólico do mito, aquele que carrega consigo a desgraça, que é o portador do mal.

O monstro mítico vem de uma ruptura com a realidade e é referido, assim, subjetivamente. As matérias parciais ressaltavam que Negromonte dizia ouvir vozes e cometia os crimes por instrução destas. Este é o ponto determinante para alocar a figura do assassino numa ruptura com os conceitos vigentes na sociedade. Por isso ele não poderia ser "apenas" um assassino ou ladrão, mas algo mais profundo, que em suas disposições gerais de símbolo abarque todas as características que são postas à vista, como o destaque à brutalidade e à mente doentia. Assim, o monstro surge como figura genérica, carregada de sentidos, que passa a representar a figura de Negromonte no nível da terceiridade, ou seja, no nível da apreensão e cognição dos sentidos.

O jornalismo, por sua vez, pode mediar o acontecimento. Os ícones que agem no processo, impregnados com a carga sígnica potencial para despertar os sentimentos relativos à figura do monstro, podem ser captados na produção midiática. Estes sentimentos, na secundidade, seriam índices que conectam tais qualidades a alguma coisa existente, estabelecendo assim a certeza de algo real. Esta certeza gerará um signo geral, o símbolo, que imbuído de tais ícones e índices, se apresentará como o monstro mítico.

Aferimos que os signos que norteiam Negromonte, os ícones que dão início ao processo semiótico e suas representações, a forma como eles são traduzidos, mediados pelo jornalismo, garantiriam a ele o significado mítico apreensível subjetiva ou objetivamente. Por isso, mesmo que a palavra monstro sequer fosse empregada, seu sentido seria inalienável. As faculdades do monstro seriam vivas no imaginário, no seu poder geral de sugerir e de significar.

Rev.Cad.Comun. Santa Maria, v.20, n.2, art 2, p.15 de 19, maio/ago.2016 


\section{CONSIDERAÇÕES FINAIS}

O monstro, quando surge na sociedade contemporânea, seria através de um acontecimento jornalístico. É um signo terceiro, um símbolo, que possui amplas capacidades de significação. O mito em si também é simbólico, pois é um tipo geral, "não é alguma coisa existente, mas uma ideia abstrata” (SANTAELLA, 2005, p. 67). O mito é capaz de carregar sentidos imbuídos na ideologia de uma sociedade e também é determinado por esta, afinal, o símbolo é definido por convenção social, o reflexo cultural de uma época, de um contexto histórico.

A imagem do monstro, seja tipificada nas suas características estéticas - grotescas, deformadas e/ou extrapoladas - ou nas suas especificidades interiores - a sociopatia, a demência, a aproximação com atos hediondos que signifiquem brutalidade para a sociedade contemporânea - é transcendental, pois vence as eras e as transformações sociais, está profundamente atrelada à cultura do homem e nela permanece viva, colorida pelos tons do imaginário.

Sendo assim, o monstro mítico e simbólico atuaria como uma forma de espelho que carrega os sentidos de repulsa e medo de uma sociedade. Sua imagem desperta sentimentos ruins e tortuosos que sugerem o mal, a bestialidade, o malefício, a ruptura da ordem social convencional e ideologicamente estabelecida. Ainda, sendo o monstro a imagem que personifica a ruptura com a realidade ideológica dos homens, a sociedade tenderia a evitá-lo, repeli-lo ou, se possível, exterminá-lo.

O jornalismo, por sua vez, funciona como um disseminador de ícones. Suas produções noticiosas não apenas eternizam os signos que caracterizam o monstro, mas mantém o mito vivo, objetiva ou subjetivamente, na consciência imaginária de uma sociedade. A partir de seus veículos impressos, online, radiofônicos e televisivos - difundem os signos relacionados ao mito do monstro e os oferecem à apreciação de uma audiência ampla.

Pode-se sugerir que esta seria a razão pela qual a figura do monstro simbólico surge de tempos em tempos no imaginário social, ressignificada através da mediação do jornalismo. Exemplos disso podem ser vistos na extensa cobertura que receberam o "Maníaco do Parque 4" e o "Caso

4 Maníaco do Parque foi alcunha recebida por Francisco de Assis, um motoboy que, em meados de 1998, estuprou e assassinou pelo menos seis mulheres, além de ter

Rev.Cad. Comun. Santa Maria, v.20, n.2, art 2, p.16 de 19, maio/ago.2016 
Nardoni 5". Essa difusão do mito a partir da retomada do monstro como acontecimento alcança um sem número de indivíduos sociais capazes de captar estes signos. Assim, o processo semiótico se dá em cada mente, despertando um sentido simbólico que evoca e ressignifica a imagem do monstro mítico que existiu, existe e existirá nos campos imaginários da sociedade, em sua função geral de ser a figura que encarna sentimentos e qualidades de punição e medo, daquilo que é ou vem do mal.

tentado assassinar outras nove. Seus crimes ocorreram no Parque do Estado, na região sul de São Paulo, SP.

5 O caso Nardoni refere-se ao assassinato da menina Isabella de Oliveira Nardoni, de cinco anos de idade. Ela foi arremessada pela janela do sexto andar do Edifício London, no distrito da Vila Guilherme, em São Paulo, em março de 2008. O caso gerou grande repercussão e tanto o pai da menina, Alexandre Nardoni, e Anna Carolina Jatobá, madrasta da criança, autores do crime, foram condenados por homicídio doloso triplamente qualificado.

Rev.Cad.Comun. Santa Maria, v.20, n.2, art 2, p.17 de 19, maio/ago.2016 
CADERNOS DE COMUNICAÇÃO

UNIVERSIDADE FEDERAL DE SANTA MARIA

\section{REFERÊNCIAS}

BERGER, Peter L.; LUCKMANN, Thomas. A construção social da realidade: tratado de sociologia do conhecimento. Pretrópolis: Vozes, 1985.

DURANT, Gilbert. As Estruturas Antropológicas do Imaginário. São Paulo: Martins Fontes, 1997.

HENN, Ronaldo. O acontecimento jornalístico em sua dimensão semiótica. IN: BE

NETTI, LEITE JUNIOR, Jorge. O que é um monstro?. Com Ciência, revista eletrônica de jornalismo científico da SBPC, 2007. Disponível em: http://www.comciencia.br/comciencia/?section $=8 \&$ edicao $=29 \&$ id $=340$

MEDITSCH, Eduardo. Jornalismo e construção social do acontecimento. IN: BENETTI, PEIRCE, Charles Sanders. Semiótica e Filosofia. São Paulo: Cultrix, 1972.

SANTAELLA, Lucia. Semiótica Aplicada. São Paulo: Cengage Learning, 2008.

SANTAELLA, Lucia. O que é semiótica?. São Paulo: Brasilliense, 2005. 


\section{Andrio J.R. dos Santos}

Graduado em Comunicação Social - Habilitação em Jornalismo, pela Universidade de Cruz Alta (Unicruz) e atualmente é mestrando no programa de Pós-Graduação em Letras Literatura da Universidade Federal de Santa Maria.

\section{Janaíne dos Santos}

Mestre em Comunicação e Informação pelo Programa de Pós-Graduação em Comunicação e Informação da UFRGS. Especialista em Gestão em Processos de Comunicação (2007) e Bacharel em Comunicação Social Habilitação Jornalismo (2004) pela UNIJUÍ. Atua como docente na Universidade de Cruz Alta desde agosto de 2010.

RECEBIDO EM: $15 / 05 / 2016$

ACEITO PARA PUBLICAÇÃO: 03/08/2016 